J. Clin. Chem. Clin. Biochem.

Vol. 24, 1986, pp. 847-860

(C) 1986 Walter de Gruyter \& Co.

Berlin - New York

\title{
The Isoelectric Focusing of Creatine Kinase Variants: II. The Heterogeneity of Creatine Kinase in Human Serum with Normal and Elevated Catalytic Concentrations ${ }^{1}$ )
}

\author{
By $E$. SiragEldin
}

Abteilung für Klinische Chemie der Medizinischen Universitätsklinik, Hamburg

G. Gercken

Institut für Biochemie und Lebensmittelchemie der Universität Hamburg and

K. Harm

Zentrallaboratorium des Allgemeinen Krankenhauses Heidberg, Hamburg

(Received December 9, 1985/June 27, 1986)

Dedicated to Prof. Dr. K. D. Voigt, Head of the Dept. of Clinical Chemistry of the University Hospital Eppendorf, Hamburg, on the occasion of his 65th birthday

Summary: An effective and reliable method for the quantitative estimation of creatine kinase-MB, creatine kinase-MM variants and mitochondrial forms of creatine kinase in serum is presented.

The high resolving power of isoelectric focusing allows the use of tetrazolium salts and meldola blue for the quantitative measurement without interfering non-specific reduction.

The addition of thiol compounds to the agarose medium increases the sensitivity of the method, due to the inhibition of sulfhydryl group oxidation, and prevents enzyme degradation, which is a possible cause of an artificial heterogeneity.

Depending upon the type of muscle and the degree of cell damage, we found 3-4 creatine kinase-MM subbands in sera with activities below $80 \mathrm{U} / 1$. At elevated creatine kinase activities 3-11 creatine kinase-MM sub-bands were found. The appearance of creatine kinase-MB in serum indicates that damage has occurred to certain organs, especially the cardiac muscle. An organ with moderate or massive cell damage could release, in addition to the sarcoplasmatic creatine kinase variants, other forms with more alkaline isoelectric points (mitochondrial creatine.kinase). The presence of such bands in serum of patients correlates with poor prognosis.

Besides the separation of creatine kinase-MM sub-bands, creatine kinase-MB, creatine kinase- $\mathrm{BB}$ and of macroforms 1 and 2, the advantage of this method is the detection of mitochondrial creatine kinase forms, which in cellulose acetate electrophoresis migrate with creatine kinase-MM.

1) I: this j. 24, 283-292 (1986). 
Isoclektrische Fokussicrung von Kreatinkinase-Varianten:

II. Dic Heterogenität der Kreatinkinase im menschlichen Serum mit normalen und erhöhten katalytischen Konzentrationen

Zusammenfassung: Es wird eine effektive und zuverlässige Methode für die quantitative Bestimmung von Kreatinkinase-MB, Kreatinkinase-MM-Varianten und mitochondrialen Formen der Kreatinkinase im Blut vorgestellt. Das hohe Auflösungsvermögen der isoelektrischen Fokussierung für die Trennung und Konzentrierung von Kreatinkinase-Varianten an ihren isoelektrischen Punkten ermöglicht die Anwendung von Tetrazoliumsalzen und Meldolablau zur quantitativen Messung ohne interferierende unspezifische Reduktion. Der Zusatz von Thiolverbindungen zum Agarosemedium erhöht die Empfindlichkeit der Methode durch Schutz der Sulfhydrylgruppen vor Oxidation und verhindert somit eine Enzyminaktivierung und eine daraus möglicherweise resultierende künstliche Heterogenität.

In Relation zum Muskeltyp und der Schwere der Zellschädigung fanden wir 3-4 Kreatinkinase-MMUnterbanden in Seren mit Aktivitäten unter $80 \mathrm{U} / \mathrm{l}$. Bei erhöhten Kreatinkinase-Aktivitäten waren 3-11 Kreatinkinase-MM-Unterbanden nachweisbar. Das Auftreten von Kreatinkinase-MB im Serum spiegelt die Schädigung bestimmter Organe, insbesondere die des Herzmuskels wider.

Ein Organ mit mäßigem oder massivem Zellzerfall kann zusätzlich zu den sarkoplasmatischen KreatinkinaseVarianten andere Formen mit alkalischeren isoelektrischen Punkten (mitochondriale Kreatinkinasen) freisetzen. Das Auftreten solcher Banden im Serum von Patienten ist ein ungünstiges prognostisches Zeichen.

Der Vorteil des Verfahrens ist außer in der Trennung von Kreatinkinase-MM-Unterbanden, KreatinkinaseMB und den Makroformen 1 und 2 im Nachweis von mitochondrialen Kreatinkinasen zu sehen, die in der Cellulose-Acetat-Folien-Elektrophorese eine ähnliche Mobilität wie Kreatinkinase-MM aufweisen.

\section{Introduction}

As the determination of the isoenzyme creatine kinase-MB in human serum is the most sensitive indicator for acute myocardial infarction $(1,2)$, an array of methods have been published for its estimation (3-8). Recently, using various methods, different creatine kinase variants were observed in human serum. The presence of such creatine kinase variants may interfere in these tests, leading to erroneous diagnosis of myocardial infarction $(9-11)$. Furthermore, the existence of certain creatine kinase variants, which upon electrophoresis migrate cathodally, anodally or with creatine kinase-MM, have been shown to correlate with poor prognosis in patients with metastatic tumours or who are otherwise seriously ill (12-16).

Recently, several authors have reported the existence of creatine kinase-MM sub-bands in human serum, but there is a lack of agreement on the number of sub-bands. Some authors have reported three (17), four (18) or five (19) creatine kinase-MM sub-bands in human blood.

In a previous publication (20) we described our findings on the heterogeneity of creatine kinase in human heart cytosol and mitochondria. The studies indicated considerable differences among these fractions in their isoelectric points, electrophoretic behaviour and response to immunoinhibition.
In the present study we have used isoelectric focusing (IEF). This new approach is superior to the aforementioned techniques, since it shows comparatively high resolution of multiple forms, high specificity and high sensitivity. In this study, the results obtained by isoelectric focusing, the immunoinhibition test and cellulose acetate electrophoresis are compared.

Evidence is presented that creatine kinase, in sera with normal or elevated activities, exists in many forms corresponding to those present in tissue extracts.

\section{Materials and Methods}

Materials

Dithiothreitol and CPK-Isotrol were obtained from Sigma Chemie, München. Creatine kinase NAC-activated and creatine kinase-MB NAC-activated test kits were from Boehringer Mannheim. 5.5-Diethylbarbituric acid and magnesium acetate were purchased from Merck, Darmstadt. Cellulose. acetate strips (Sartorius membrane filter type SMN 11200 BD $5.7 \times$ $4.5 \mathrm{~cm}$ ) were obtained from Beckman, München. Ampholine pH 3.5-9.5 Cat. No. 1818-101 and Ampholine pH 5-8 Cat. No. 1818-126 were obtained from LKB, Bromma.

\section{Methods}

Quantitative determination of creatine kinase activities

The optimized spectrophotometric method based on the recommendations of the German Society for Clinical Chemistry (21) was used to measure total creatine kinase activity with a Hitachi Rate Anălyser at $25^{\circ} \mathrm{C}$.

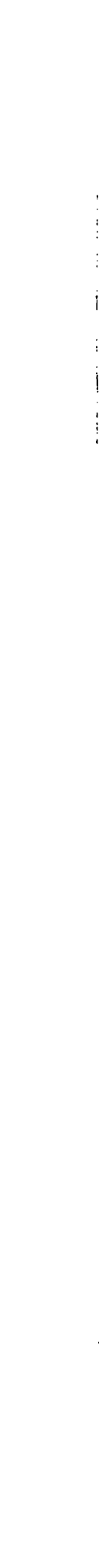


Creatine kinase-MB was determined at $25^{\circ} \mathrm{C}$ after immunological inhibition of creatine kinase-M subunits by specific antiM-antibodies.

\section{Cellulose acetate electrophoresis}

Cellulose acetate electrophoresis was performed in a Boskamp microphor chamber with a running buffer of $73 \mathrm{mmol} / 1$ trisbase and $24 \mathrm{mmol} / \mathrm{l}$ barbituric acid supplemented with $1 \mathrm{mmol} / 1$ dithiothreitol, $\mathrm{pH}$ at 8.6 , for $35 \mathrm{~min}$ at 300 volts and $6-8^{\circ} \mathrm{C}$. A creatine kinase control (CPK-ISOTROL) was used as a marker. A detailed description of the method has been published elsewhere (10).

We applied 2 to $3 \mu \mathrm{l}$ rof sample either untreated or preincubated with anti-creatine kinase- $M$, as published previously (22), with slight modification. Briefly, $100 \mu \mathrm{l}$ of sample werc mixed for one minute with $5 \mu$ l of anti-creatine kinase-M-antibodies (Merck No. 14326). The content of one vial was dissolved in $400 \mu \mathrm{l}$ of test buffer instead of $2500 \mu \mathrm{l}$ and incubated for 12 min at room temperature.

After electrophoresis, creatine kinase-isoenzyme bands were visualized by placing the membrane on agar purum (Behringwerke AG, Marburg) plates containing the reaction medium, followed by incubation for $35 \mathrm{~min}$ at $37^{\circ} \mathrm{C}$.

\section{Thin layer isoelectric focusing of creatine kinase-isoenzymes on} Isogel agarose

For thin layer isoelectric focusing, we used a LKB model 2217 Ultrophor. The procedures for the preparation of the thin layer gel were as described by the manufacturer (23), except that the following modifications were found necessary for an adequate separation of creatine kinase-isoenzymes:

a) Small wells were constructed using tesa film,

b) 2-mercaptoethanol at a final concentration of $2.5 \mathrm{mmol} / 1$ was added to the agarose solution at $65^{\circ} \mathrm{C}$ followed by the Ampholine and

c) the gel was kept overnight at $4-6^{\circ} \mathrm{C}$ before use.

Isoelectric focusing was performed by applying $2-4 \mu \mathrm{l}$ serum to the $\mathrm{pH} 3.5-9.5$ or $\mathrm{pH} 5-8$ agarose gels.

\section{Detection of creatine kinase activity bands after thin layer isoelec- tric focusing}

The following reaction medium was prepared:

Solution A: One volume of $2 \%$ agar purum was heated to boiling in distilled water and transferred to a water bath at $43^{\circ} \mathrm{C}$.

Solution B: One volume of the concentrated reaction medium for the quantitative determination of creatine kinase (10) was kept at $37^{\circ} \mathrm{C}$. Nitroblue tetrazolium $(10 \mathrm{mg})$ and meldola blue $(0.5 \mathrm{mg})$ were added to $10 \mathrm{ml}$ of solution $\mathrm{A}$ and mixed thoroughly.

An equal volume of solution $B$ was mixed with solution $A$, poured onto the thin layer gel and incubated for $35 \mathrm{~min}$ at $37^{\circ} \mathrm{C}$ in the dark. The zymogram was then removed and transferred to $10 \%$ acetic acid. To dry the agarose film, a thick filter paper was carefully layered on the top of the gel followed by a glass plate and a weight of about $1 \mathrm{~kg}$. After $10 \mathrm{~min}$, the filter was removed and the gel was dried with a stream of cold air. The formazane bands at the sites of creatine kinase activity were traced with a Beckman model CDS-200 densitometer at $520 \mathrm{~nm}$.

Creatine kinase-MB activity is either expressed as absolute activity $(\mathrm{U} / \mathrm{i})$ or as a percentage or fraction of the total creatine kinase activity. With the IEF method, creatine kinase-MB was measured as a percentage or fraction of the total creatine kinase activity using the relative peak height of the creatine kinase$\mathrm{MB}$ band. When it was necessary to express creatine kinase$\mathrm{MB}$ as enzyme activity (U/l) the total creatine kinase activity was multiplied by the percentage or fraction of creatine kinaseMB.

Titration curve of creatine kinase-isoenzymes by $0.5 \mathrm{~mm}$ thin layer isoelectric focusing using Ampholine pH-ranges 3.5-9.5 or 5-8 in Isogel agarose

\section{Preparation of the mould}

A trench in the middle of the glass was constructed simply by cutting two pieces of tesa film about $10 \mathrm{~cm}$ long and $2 \mathrm{~mm}$ wide and then applying them to the middle of the glass plate with a spacer $(125 \times 240 \mathrm{~mm})$. A second trench was constructed in the same way and the glass plate was then left overnight to dry.

\section{The titration curve procedure}

The gel was prepared as described previously.

1. First dimension isoelectric focusing. This was done without adding the sample.

Voltage and current were set to maximum and the isoelectric focusing was started by applying 500 volts with increasing the power to about $6 \mathrm{~W}$. The isoelectric focusing was performed for 25 min for Ampholine $\mathrm{pH}$ 3.5-9.5 and 40 minutes for Ampholine pH 5-8. These conditions were sufficient to generate a stationary $\mathrm{pH}$-gradient. At this stage, the electrode strips were removed and the gel layers underneath were removed.

The $\mathrm{pH}$-gradient formed was checked with a surface electrode type 2117-222 (LKB).

2. The sample to be analysed $(25 \mu \mathrm{l})$ was applied to the trench.

New electrodes were impregnated with anode and cathode solutions (23) and applied perpendicular to the first run. The second dimension electrophoresis then was carried out for 12 $\min$ at 600 volts.

3. The detection of creatine kinase activity was performed using the direct staining technique as described previously.

\section{Results}

\section{Detection limit and linearity}

For the detection limit and linearity of the IEF, serial dilutions from the serum of a patient with a proven myocardial infarction were examined using human serum with no detectable creatine kinase activity as diluent.

The series covered the range of $116-928 \mathrm{U} / \mathrm{l}$ and 8-64 U/l of total creatine kinase and creatine kinase$\mathrm{MB}$, respectively. Three microliters of each dilution were applied to the IEF gel.

Figure $1 \mathrm{a}$ shows that the method is linear up to 700 $\mathrm{U} / \mathrm{l}$ of total creatine kinase. The lowest creatine kinase value that could be distinguished from zero was $6 \mathrm{U} / \mathrm{l}$. When IEF is compared with the immunoinhibition test within the above mentioned range, a correlation coefficient of $0.992(n=7)$ is found. 


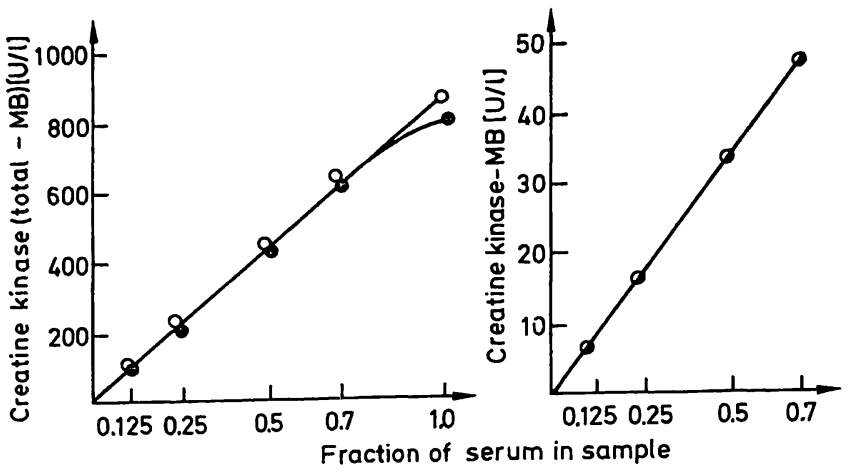

Fig. 1 a. Linearity of the IEF method $(0-0)$ for the measurement of total creatine kinase (minus creatine kinaseMB) activities compared with spectrophotometric methods $(0-0)$.
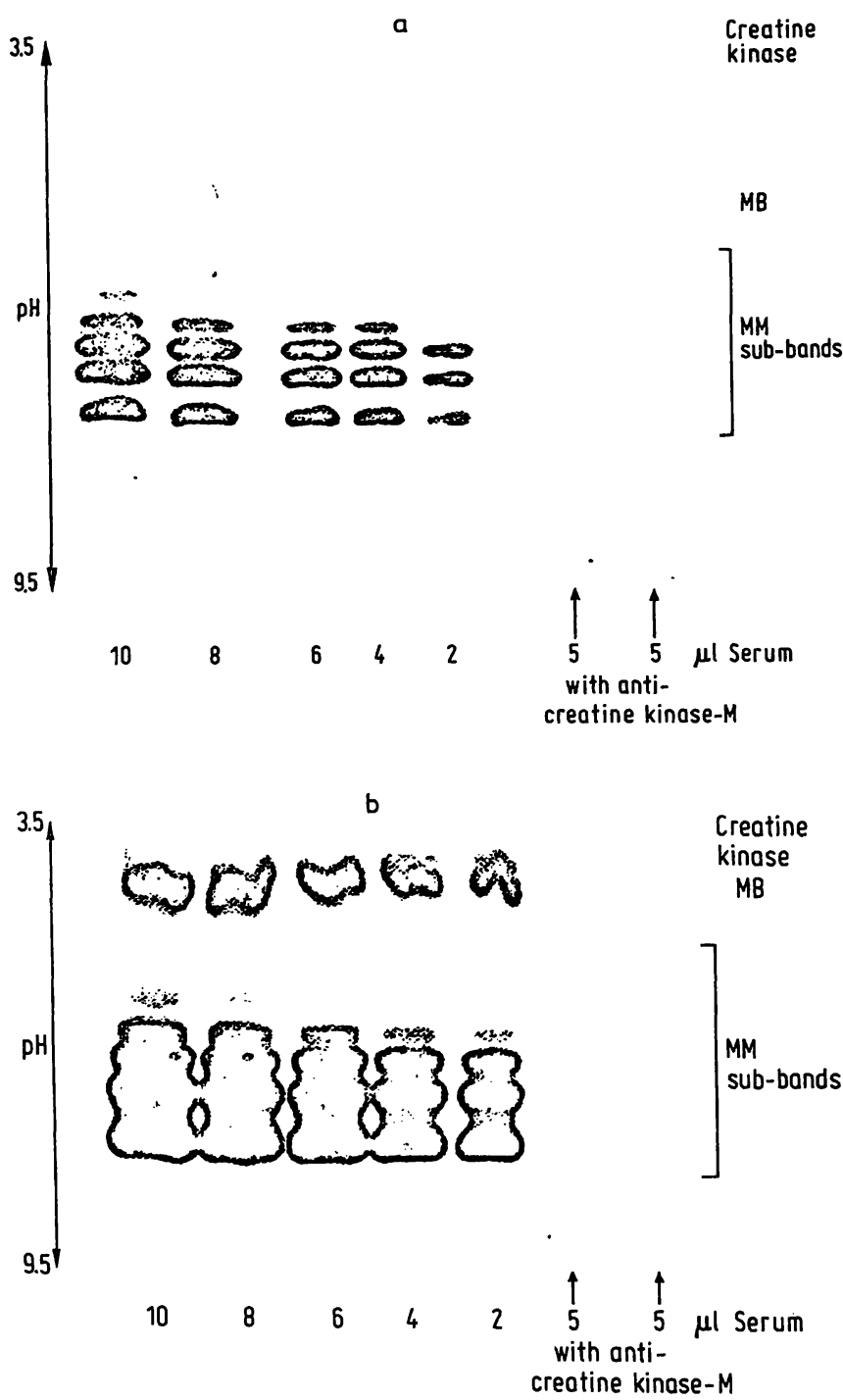

Fig. 1 b. Number of creatine kinase-MM sub-bands obtained by isoelectric focusing in the pH-range $3.5-9.5$ in relation to the applied amount of total creatine kinase activity. The sera were obtained from a patient (a) who had undergone myocardial surgery ( $944 \mathrm{U} / 1$ total creatine kinase, $13 \mathrm{U} / 1$ creatine kinase-MB) and a patient (b) with proven myocardial infarction (2097 $\mathrm{U} / \mathrm{l}$ total creatine kinase, $193 \mathrm{U} / \mathrm{l}$ creatine kinase-MB).
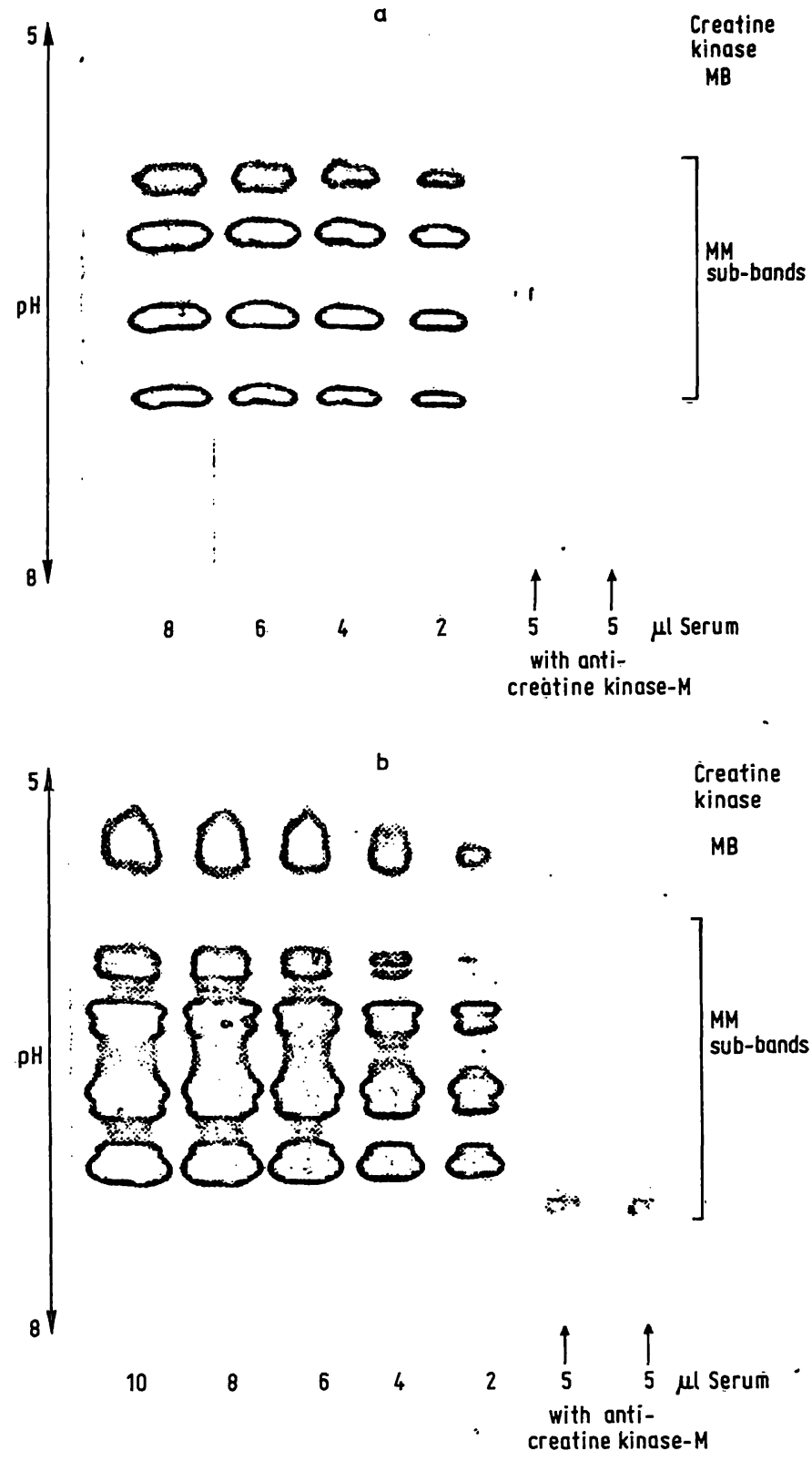

Fig. $1 \mathrm{c}$. Number of creatine kinase-MM sub-bands by isoelectric focusing in the pH-range $5-8$ in relation to the applied amount of total creatine kinase activity. The sera applied were the same as described in fig. $1 \mathrm{~b}$.

The number of creatine kinase-MM sub-bands was not related to the applied total creatine kinase activity (fig. $1 \mathrm{~b}$ ) but to the pH-range used (fig. $1 \mathrm{c}$ ). To prove that the bands obtained were true creatine kinaseMM sub-bands, sera were treated with anti-creatine kinase-M-antibodies before isoelectric focusing. After this treatment the bands disappeared in the $\mathrm{pH}$-range $3.5-9.5$ as well as in the pH-range $5-8$ (fig. $1 \mathrm{~b}$ and $1 \mathrm{c}$ ).

\section{Within-run-precision}

We evaluated the within-run-precision by making multiple applications to IEF gels of a serum sample 
obtained from a patient with proven myocardial infarction. All patterns were scanned as described in "methods".

The creatine kinase-MB activities as estimated by both the immunoinhibition test and IEF are summarized in table 1.

The CVs were $1.5 \%$ for total creatine kinase, $6 \%$ for immunologically measured creatine kinase-MB and $7 \%$ for creatine kinase-MB determined by IEF.

Tab. 1. Within-run-precision of the immunoinhibition test and IEF.

\begin{tabular}{|c|c|c|c|}
\hline & \multicolumn{2}{|c|}{ Continuous methods } & \multirow{2}{*}{$\begin{array}{l}\text { Isoelectric } \\
\text { focusing } \\
\text { Creatine } \\
\text { kinase-MB } \\
(\mathrm{U} / \mathrm{l})\end{array}$} \\
\hline & $\begin{array}{l}\text { Total creatine } \\
\text { kinase } \\
(\mathrm{U} / \mathrm{l})\end{array}$ & $\begin{array}{l}\text { "Creatine } \\
\text { kinase-MB" } \\
(\mathrm{U} / \mathrm{l})\end{array}$ & \\
\hline$\overline{\mathbf{x}}$ & 519 & 33 & 34 \\
\hline $\mathrm{SD}$ & 7.6 & 1.9 & 2.5 \\
\hline CV $(\%)$ & 1.5 & 6 & 7 \\
\hline n & 9 & 9 & 9 \\
\hline
\end{tabular}

$\mathrm{n}=$ number of assays, $\overline{\mathrm{x}}=$ mean value, $\mathrm{SD}=$ standard deviation, $\mathrm{CV}=$ coefficient of variation.

"Creatine kinase-MB" = immunoinhibition test.

\section{Between-run-precision}

Aliquots of frozen $\left(-20^{\circ} \mathrm{C}\right)$ serum obtained from a patient with proven myocardial infarction were analysed by both the kinetic methods and IEF.

The data for the precision of the IEF-Isogel method from day-to-day as compared to the immunoinhibition test are shown in table 2 . The CVs were $3.1 \%$ for total creatine kinase and $11 \%$ for immunological creatine kinase-MB. Using the IEF method the CV for creatine kinase-MB was $10 \%$, compared with CVs of $7.8 \%, 3.2 \%, 4.8 \%$ and $10 \%$ for the creatine $k i-$ nase-MM sub-bands $1-4$, respectively.
The transfer of creatine kinase-MM and creatine kinase-MB, separated by cellulose acetate electrophoresis, to thin layer isoelectric focusing gels

Three sera, two from patients suffering from proven myocardial infarction and one from a muscle trauma patient, were separated by cellulose acetate electrophoresis as described above. Figure 2 a demonstrates the patterns obtained by cellulose acetate electrophoresis. The sera of both patients suffering from myocardial infarction showed creatine kinase-MM and creatine kinase-MB bands, while the patient with muscle trauma exhibited only a creatine kinase-MM band in his serum. The unstained creatine kinase bands corresponding to creatine kinase-MM and creatine kinase-MB were cut out and layered carefully onto the surface of the thin layer isoelectric focusing gel. The corresponding serum samples $(3-4 \mu \mathrm{l})$ were also loaded onto the thin layer gel. All samples were focused and stained as described in "methods".

Figure $2 \mathrm{~b}$ demonstrates the patterns obtained as a result of the transfer of the cellulose acetate strips to the isoelectric focusing gel. The creatine kinase-MM bands obtained after electrophoresis showed a heterogeneity ranging from 4 to 5 sub-bands similar to those obtained by direct analysis of the sera by isoelectric focusing. To prove that the above bands were really creatine kinase-MM, the serum was incubated with anti-creatine kinase-M-antibodies. After IEF no subbands were seen. The creatine kinase-MB separated by electrophoresis reveals only one band in the $\mathrm{pH}$ range 3.5-9.5 when IEF was used.

Figure 3 depicts two titration curves from a serum of a patient with proven myocardial infarction, using Ampholine pH 3.5-9.5 (a) and Ampholine pH 58 (b) in Isogel agarose. Both curves show clearly that the creatine kinase-MM isoenzyme was split into subbands with different isoelectric points. The creatine kinase-MB isoenzyme was focused at $\mathrm{pH}$ 5.5.

Tab. 2. Between-run-precision of the immunoinhibition test and IEF.

\begin{tabular}{|c|c|c|c|c|c|c|c|}
\hline & \multicolumn{2}{|c|}{$\begin{array}{l}\text { Continuous mẹthods } \\
(\mathrm{U} / \mathrm{l})\end{array}$} & \multicolumn{5}{|c|}{$\begin{array}{l}\text { Isoelectric focusing } \\
(\mathrm{U} / \mathrm{l})\end{array}$} \\
\hline & $\begin{array}{l}\text { Total } \\
\text { creatine kinase }\end{array}$ & $\begin{array}{l}\text { "Creatine } \\
\text { kinase-MB" }\end{array}$ & MM1 & MM 2 & MM 3 & MM 4 & $\begin{array}{l}\text { Creatine } \\
\text { kinase-MB }\end{array}$ \\
\hline $\begin{array}{l}\bar{x} \\
\text { SD } \\
\text { CV }(\%) \\
n\end{array}$ & $\begin{array}{c}293 \\
9 \\
3.1 \\
10\end{array}$ & $\begin{array}{r}27 \\
3 \\
11 \\
10\end{array}$ & $\begin{array}{c}53 \\
4 \\
7.8 \\
10\end{array}$ & $\begin{array}{c}87 \\
2.8 \\
3.2 \\
10\end{array}$ & $\begin{array}{c}109 \\
5.2 \\
4.8 \\
10\end{array}$ & $\begin{array}{l}15 \\
1.6 \\
10 \\
10\end{array}$ & $\begin{array}{l}29 \\
2.9 \\
10 \\
10\end{array}$ \\
\hline
\end{tabular}

$\mathrm{n}=$ number of assays, $\overline{\mathbf{x}}=$ mean value, $\mathrm{SD}=$ standard deviation, $\mathrm{CV}=$ coefficient of variation, "creatine kinase-MB" $=$ immunoinhibition test. 

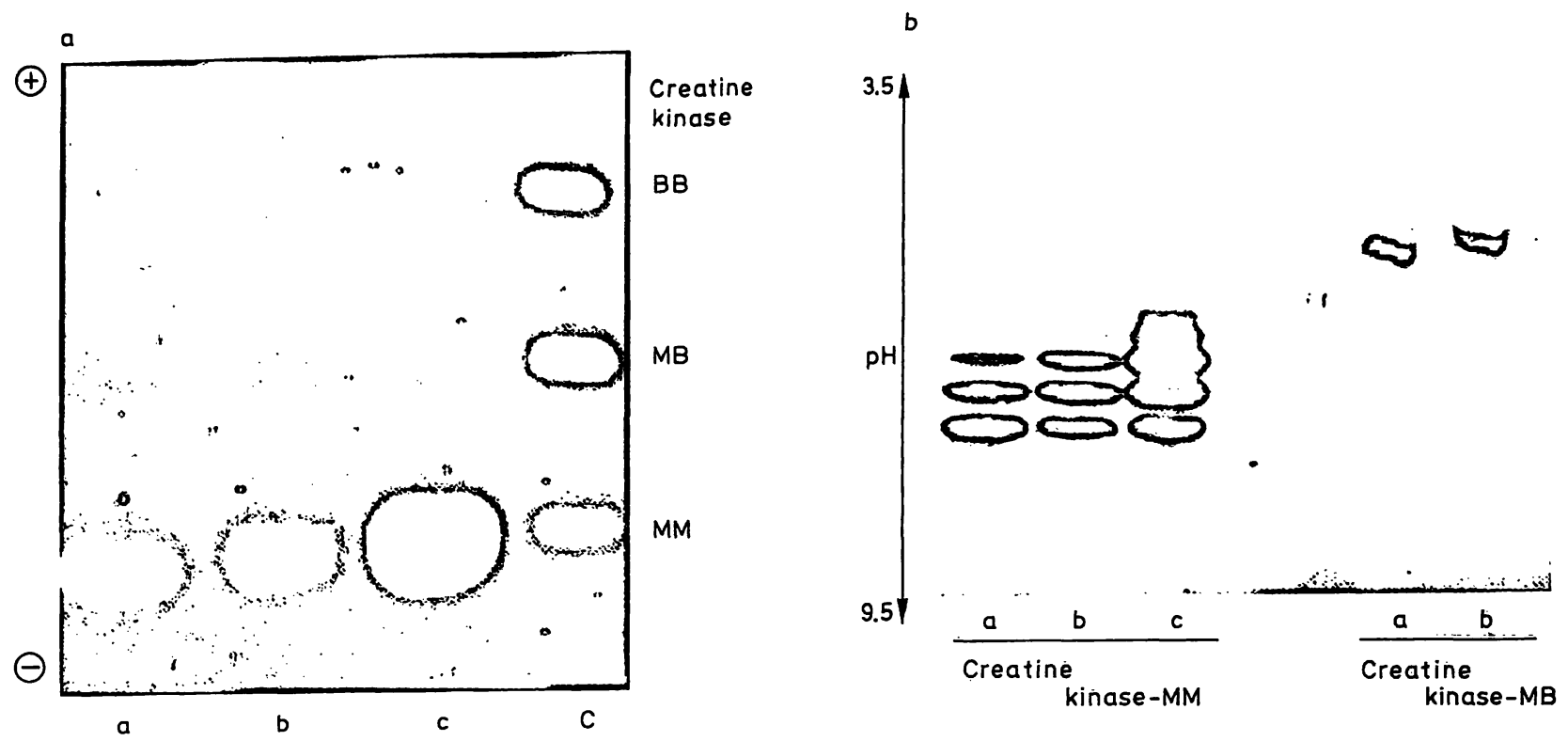

Fig. 2. Migration patterns of creatine kinase isoenzymes from patients with myocardial infarction (a, b) and muscle trauma (c). $\mathrm{C}=\mathrm{CPK}$ Isotrol. a) Electrophoresis on cellulose acetate strips at $\mathrm{pH} 8.6$. b) Isoelectric focusing in the $\mathrm{pH}-\mathrm{range} 3.5-$ 9.5. The samples $a, b$, and $c$ were separated by cellulose acetate electrophoresis and the bands containing creatine kinase$\mathrm{MB}$ and creatine kinase-MM isoenzymes were cut out, transferred to Isogel agarose and subjected to isoelectric focusing.

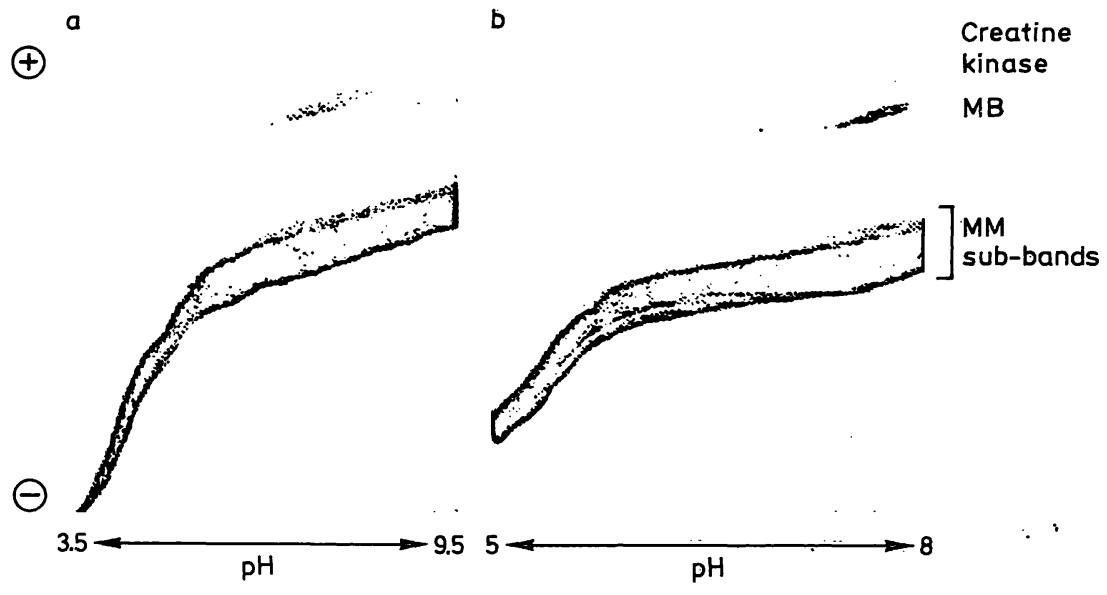

Fig. 3. Titration curves on Isogel agarose in the pH-range 3.5-9.5 (a) and 5-8 (b). The serum was obtained from a patient with proven myocardial infarction with $1070 \mathrm{U} / 1$ and $107 \mathrm{U} / 1$ for total creatine kinase and creatine kinase-MB, respectively. The creatine kinase bands were visualised with meldola blue and nitroblue tetrazolium, using an overlay technique.

Investigations of sera from different groups of patients

We selected patients with normal and elevated creatine kinase activities without myocardial affections and patients with proven myocardial infarction and myocardial surgery. All specimens with a total creatine kinase activity of more than $700 \mathrm{U} / \mathrm{l}$ were diluted with saline before isoelectric focusing.

Figure 4 represents the means of different creatine kinase-MM sub-band activities from patients with normal and elevated creatine kinase. The creatine kinase-MM sub-bands were obtained using an Ampholine $\mathrm{pH} 3.5-9.5$ gradient in Isogel agarose. It can be observed from figure 4 that creatine kinaseMM sub-bands are present in sera of patients with normal creatine kinase activity $(-80 \mathrm{U} / \mathrm{l})$ as well as in those with elevated creatine kinase activities. In the last group, however, a distinct creatine kinaseMM sub-band 5 could be seen.

Figure 5 shows the frequency distribution of creatine kinase-MM sub-bands in the two groups mentioned above. The $x$-axis represents the percentage activity of creatine kinase-MM sub-bands from total creatine kinase, while the absolute frequency is scaled on the y-axis. Each block represents one patient. The distribution of the creatine kinase-MM sub-bands 


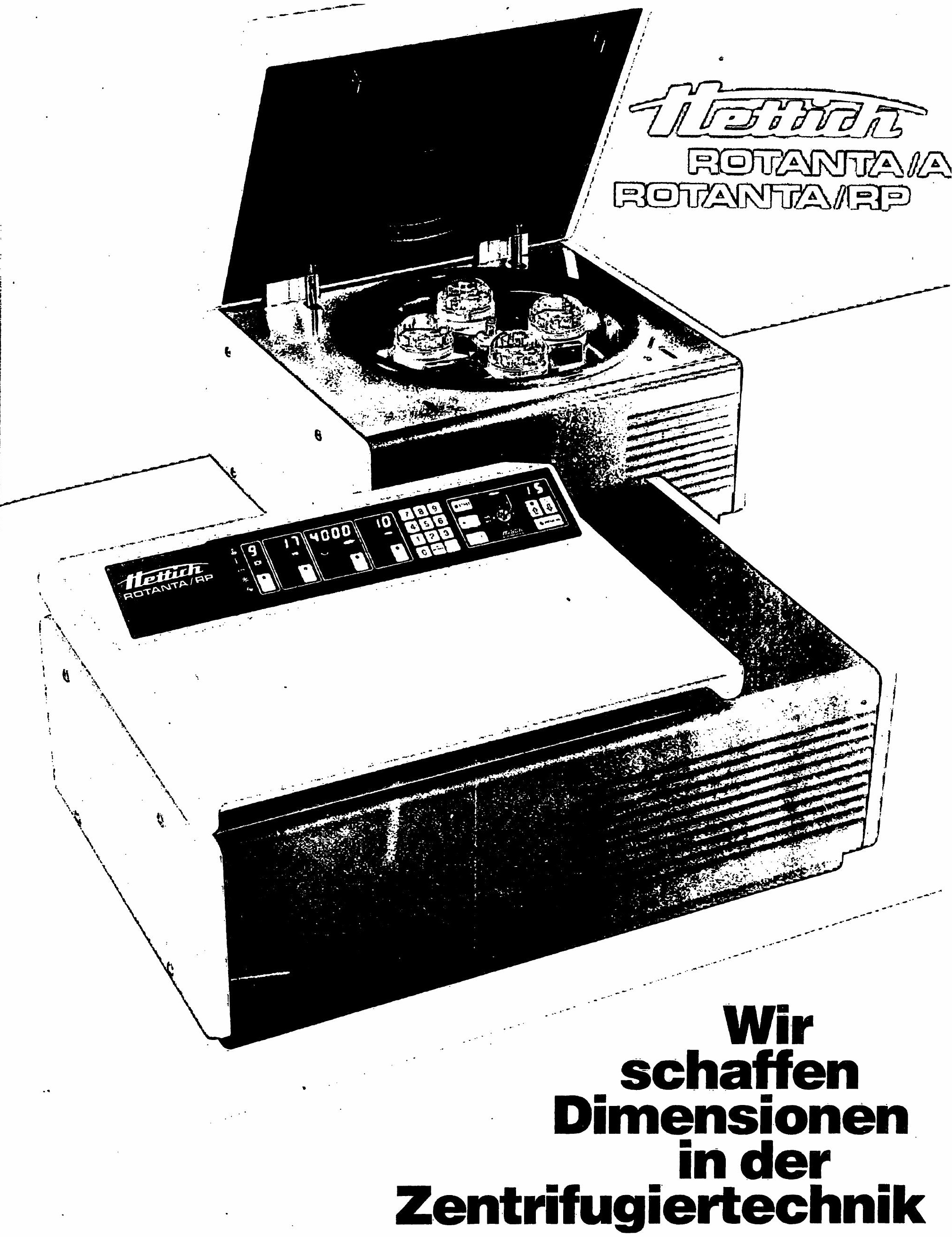




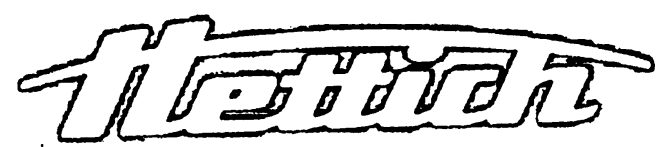

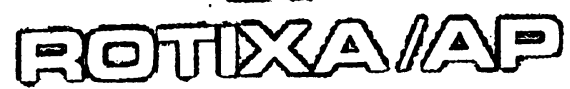

GILXA/回回
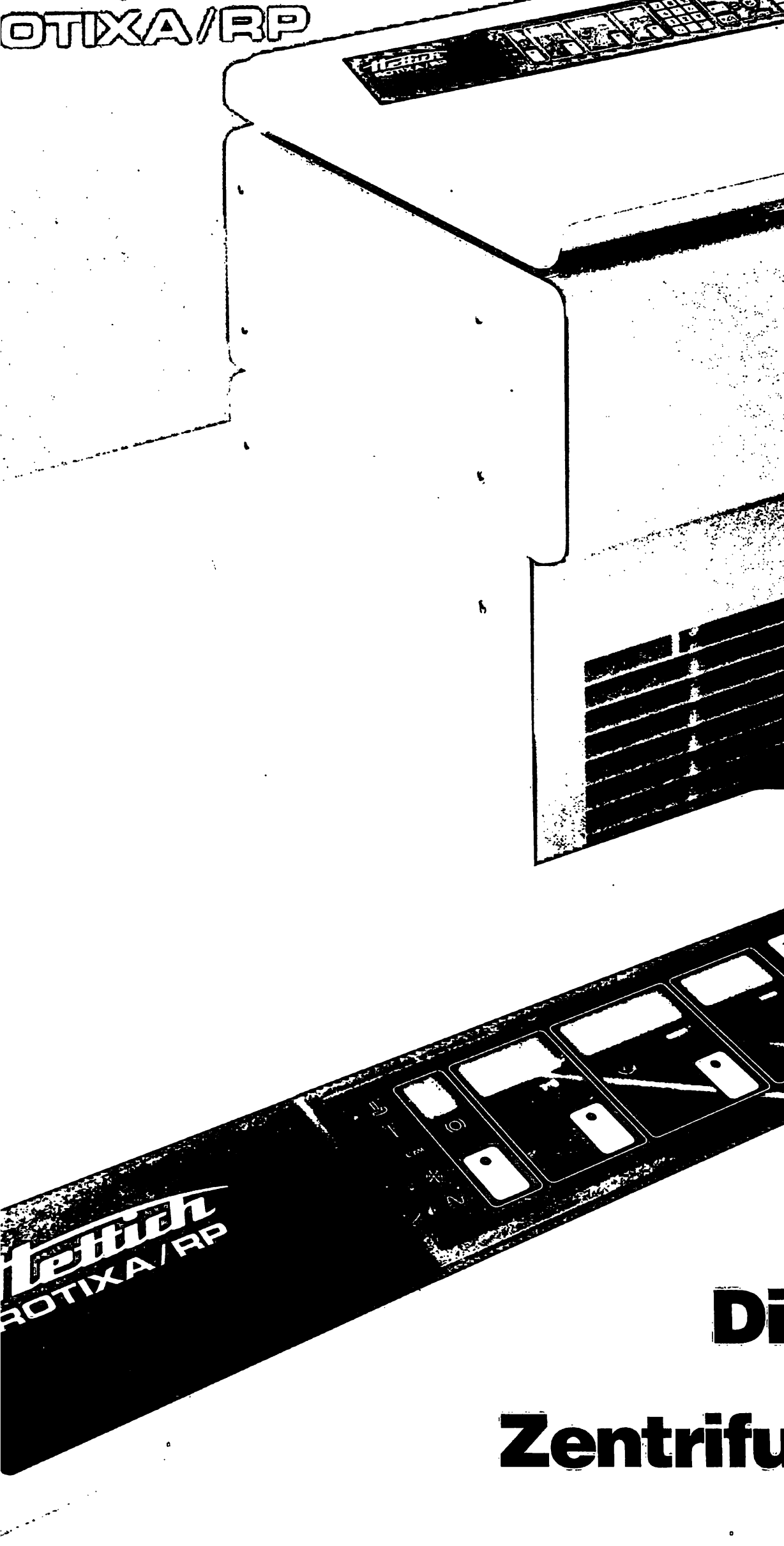

\section{Zentrifugiertechnik}

Wir

Andreas Hettich - Postfach 260 - D-7200 Tuttlingen - Telefon (07461) 705-0 

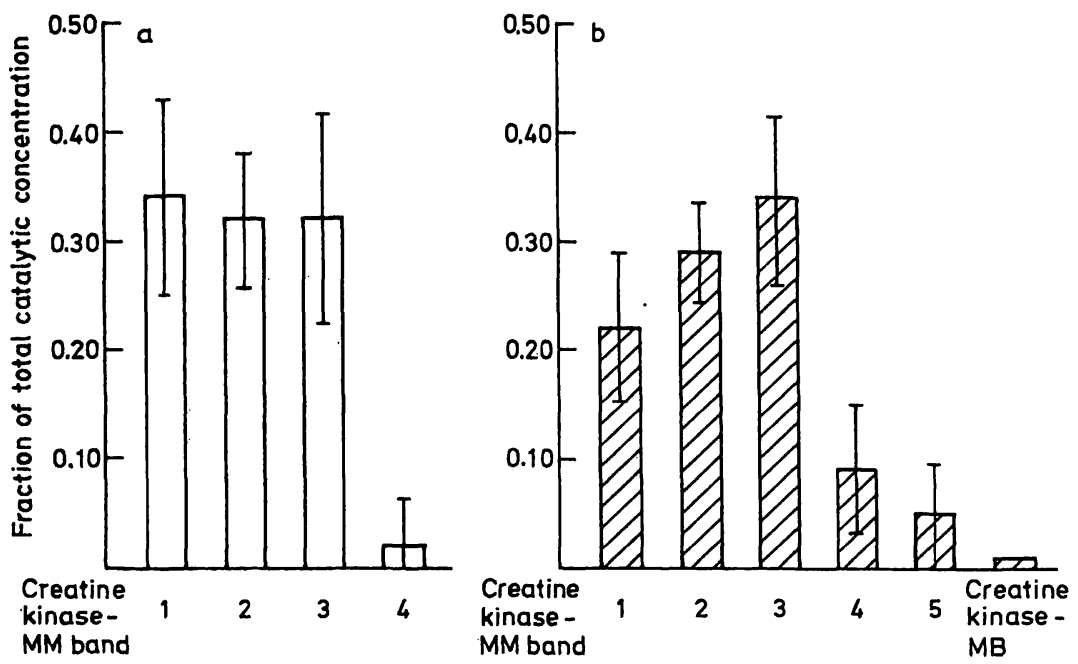

Fig. 4. Means of different creatine kinase-MM sub-band activities as a fraction of total creatine kinase in sera of patients with normal (a) and elevated (b) creatine kinase activities. Creatine kinase-MB was only present in group b. The y-axis represents the fraction of total creatine kinase and the $\mathrm{x}$-axis the creatine kinase-MB sub-bands $1-5$ and creatine kinaseMB. The method applied was IEF on Isogel agarose with Ampholine pH 3.5-9.5. The standard deviations are indicated.
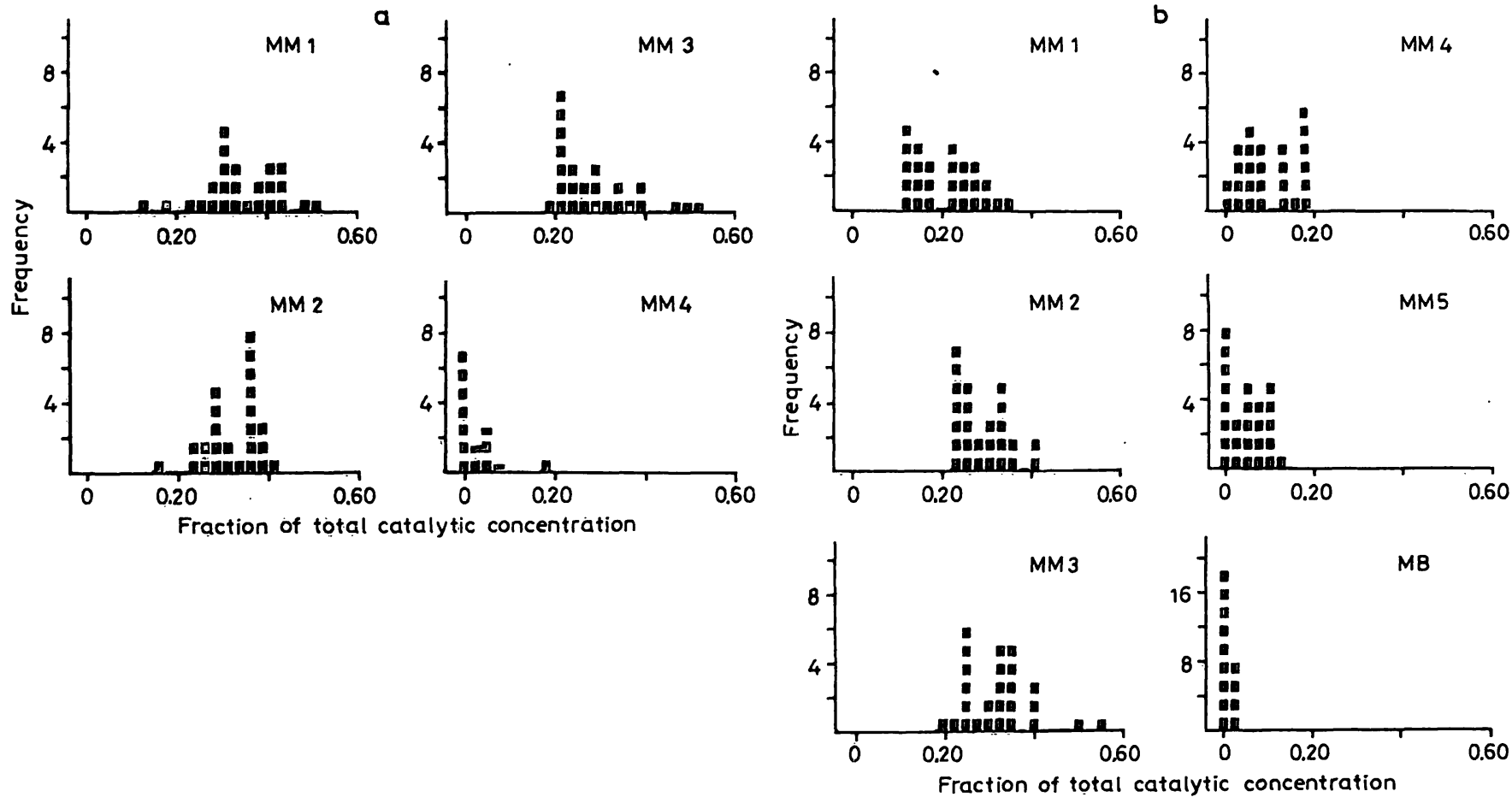

Fig. 5. Absolute frequencies of different creatine kinase-MM sub-bands and creatine kinase-MB versus activities of these bands as a fraction of total creatine kinase activity. a) sera of patients with normal and b) sera of patients with elevated creatine kinase activities.

fluctuates within the same group. No creatine kinase$\mathrm{MB}$ band was observed in patients with normal creatine kinase activity. In some patients with elevated total creatine kinase activity, the presence of creatine kinase-MB was shown with the immunoinhibition test and IEF, but it did not exceed $4 \%$ of the total creatine kinase activity. A good correlation between the two methods ( $\mathrm{r}=0.987$ ) was found.
In the sera of 50 myocardial infarction patients, values of 99 to $2213 \mathrm{U} / \mathrm{l}$ were found for total creatine kinase. Values of 10 to $214 \mathrm{U} / \mathrm{l}$ and 13 to $171 \mathrm{U} / \mathrm{l}$ for creatine kinase-MB were found with IEF and the immunoinhibition test, respectively. Twenty three of these were also analysed with cellulose acetate electrophoresis in order to compare the method with IEF (table 3). A satisfactory correlation $(r=0.87)$ was 
Tab. 3. Creatine kinase activities in sera of patients with proven myocardial infarction measured by the immunoinhibition test ("creatinc kinase-MB"), cellulose acetate electrophoresis and isoelectric focusing on Isogel agarose.

\begin{tabular}{|c|c|c|c|c|c|c|c|c|c|c|}
\hline \multirow{4}{*}{ Nr. } & \multicolumn{2}{|c|}{ Continuous methods } & \multirow{2}{*}{\multicolumn{2}{|c|}{$\begin{array}{l}\text { Cellulose acetatc } \\
\text { electrophoresis }\end{array}$}} & \multicolumn{6}{|c|}{ Isoelectric focusing } \\
\hline & \multirow{3}{*}{$\begin{array}{l}\text { Total } \\
\text { creatine } \\
\text { kinase } \\
(U / 1)\end{array}$} & \multirow{3}{*}{$\begin{array}{l}\text { "Creatine } \\
\text { kinase-MB" } \\
(\%)\end{array}$} & & & \multirow{3}{*}{ 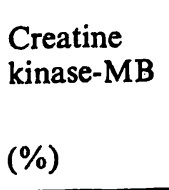 } & & & & & \\
\hline & & & \multirow{2}{*}{$\begin{array}{l}\text { Creatine } \\
\text { kinase-MM } \\
(\%)\end{array}$} & \multirow{2}{*}{ 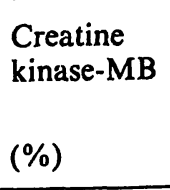 } & & \multirow{2}{*}{$\begin{array}{l}\text { MM1 } \\
\text { (\%) }\end{array}$} & \multirow{2}{*}{$\begin{array}{l}\text { MM2 } \\
(\%)\end{array}$} & \multirow{2}{*}{$\begin{array}{l}\text { MM3 } \\
(\%)^{\cdot /}\end{array}$} & \multirow{2}{*}{$\begin{array}{l}\text { MM4 } \\
(\%)\end{array}$} & \multirow{2}{*}{$\begin{array}{l}\text { MM5 } \\
(\%)\end{array}$} \\
\hline & & & & & & & & & & \\
\hline 1 & 301 & 15 & 81 & 19 & 19 & 33 & 32 & 16 & - & - \\
\hline 2 & 405 & 23 & 72 & 28 & 27 & 23 & 28 & 18 & 4 & - \\
\hline 3 & 294 & 11 & 89 & 11 & 6 & 11 & 23 & 34 & 17 & 9 \\
\hline 4 & 391 & 9 & 89 & 11 & 7 & 32 & 34 & 20 & 7 & - \\
\hline 5 & 691 & 10 & 88 & 12 & 9 & 25 & 31 & 24 & 8 & 3 \\
\hline 6 & 371 & 18 & 78 & 22 & 24 & 25 & 27 & 22 & 2 & - \\
\hline 7 & 1723 & 8 & 86 & 14 & 12 & 29 & 32 & 24 & 3 & - \\
\hline 8 & 1432 & 9 & 88 & 12 & 13 & 25 & 29 & 25 & 8 & - \\
\hline 9 & 436 & 16 & 86 & 14 & 13 & 13 & 23 & 38 & 8 & 5 \\
\hline 10 & 1178 & 7 & 93 & 7 & 11 & 23 & 29 & 28 & 9 & - \\
\hline 11 & 2136 & 8 & 89 & 11 & 10 & 33 & 31 & 21 & 5 & - \\
\hline 12 & 1524 & 8 & 89 & 11 & 10 & 28 & 31 & 26 & 5 & $-\cdot$ \\
\hline 13 & 790 & 9 & 91 & 9 & 6 & 16 & 30 & 36 & 12 & - \\
\hline 14 & 735 & 11 & 91 & 9 & 8 & 24 & 31 & 29 & 8 & - \\
\hline 15 & 718 & 10 & 90 & 10 & 12 & 21 & 22 & 34 & 11 & - \\
\hline 16 & 1122 & 9 & 87 & 13 & 10 & 26 & 31 & 26 & 7 & - \\
\hline 17 & 684 & 10 & 86 & 14 & 10 & 41 & 32 & 17 & - & - \\
\hline 18 & $425^{\circ}$ & 12 & 84 & 16 & 11 & 28 & 31 & 22 & 8 & - \\
\hline 19 & 451 & 12 & 86 & 14 & 9 & 26 & 32 & 27 & 6 & - \\
\hline 20 & 415 & 6 & 91 & 9 & 10 & 26 & 32 & 27 & 3 & 2 \\
\hline 21 & 349 & 16 & 74 & 26 & 23 & 18 & 28 & 23 & 5 & 3 \\
\hline 22 & 345 & 13 & 87 & 13 & 22 & 25 & 29 & 22 & 2 & $=$ \\
\hline 23 & 1281 & 6 & 89 & 11 & 11 & 10 & 31 & 29 & 19 & - \\
\hline
\end{tabular}

"Creatine kinase-MB" = immunoinhibition test.

found between cellulose acetate electrophoresis and the IEF method. This is also true for the immunoinhibition test and IEF ( $\mathrm{r}=0.85)$.

The mean activities obtained for creatine kinase-MM sub-bands and creatine kinase-MB are demonstrated in figure $6 \mathrm{a}$. Between 3 and 5 creatine kinase-MM sub-bands were detected by using Ampholine $\mathrm{pH}$ $3.5-9.5$.

This is also the case for sera from patients undergoing cardiosurgery. In this group we observed a creatine kinase-MB band, in addition to the 3-5 creatine kinase-MM sub-bands (fig. 6 b).

The standard deviation of creatine kinase-MB in patients with myocardial infarction is larger than that observed in cardiosurgery patients (fig. 7). The distribution of creatine kinase-MM sub-bands in both groups is very different. The creatine kinaseMB activity in patients with myocardial infarction was more than $6 \%$ of the total creatine kinase activity. In cardiosurgery patients, creatine kinase-MB values below or above $6 \%$ were observed.

The creatine kinase patterns shown in figure 8 were found in four samples from different patients. Sample $\mathrm{c}$ was drawn from a patient with muscular trauma and sample $\mathrm{d}$ from a patient undergoing myocardial surgery. Samples a and $b$, which contained total creatine kinase activities of $58 \mathrm{U} / 1$ and $60 \mathrm{U} / 1$ respectively, showed 3 creatine kinase-MM sub-bands in IEF. 11 Creatine kinase-MM sub-bands were detected in samples $c$ and $d$, which contained $1083 \mathrm{U} / 1$ or $1168 \mathrm{U} / 1$ total creatine kinase and $20 \mathrm{U} / 1$ or 108 $\mathrm{U} / 1$ creatine kinase-MB, respectively. A correlation between the immunoinhibition test and both the cellulose acetate and IEF methods was not observed in patients with falsely elevated immunological "creatine kinase-MB" values (table 4).

In 10 out of 12 sera the creatine kinase-MB activity, as measured by the immunoinhibition test, was found to be between $6-30 \%$ of the total creatine kinaseactivity. In contrast, no creatine kinase-MB band was observed by either cellulose acetate electrophoresis or IEF. Five out of 12 patients were suffering from coronary heart diseases and had undergone surgical operations. In the 3 patients suffering from myocardial infarction, the samples were taken in the late phase of the infarction.

The serum with the high creatine kinase-MB activity $(42 \mathrm{U} / 1=30 \%)$ was obtained from a patient after laryngectomy. Nine out of 12 sera showed a high : :

J. Clin. Chem. Clin. Biochem. / Vol. 24, 1986 / No. 11 

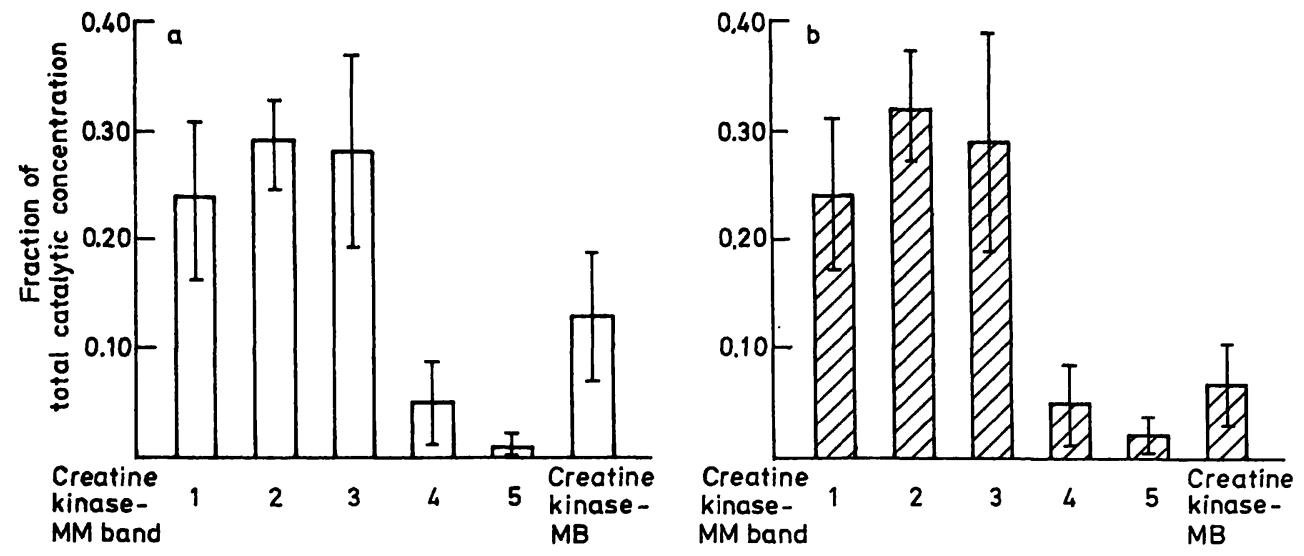

Fig. 6. Means of the creatine kinase-MM sub-band and creatine kinase-MB activities, measured as fractions of total creatine kinase activities in sera from patients with myocardial infarction (a) and undergoing cardiosurgery (b).
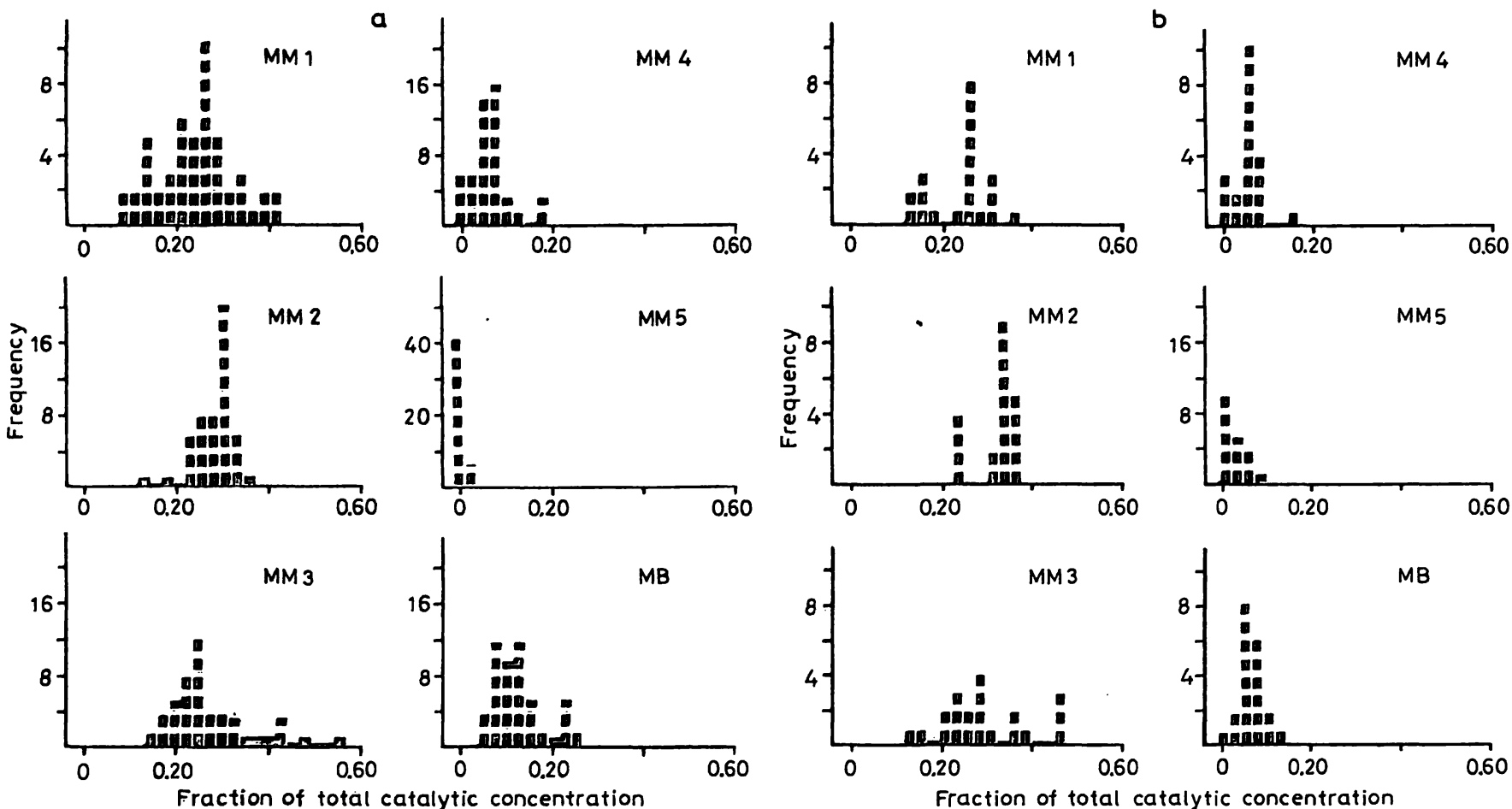

Fig. 7. Absolute frequencies of different creatine kinase-MM sub-bands and creatine kinase-MB versus activities of these bands as fraction of total creatine kinase activity in sera of patients with myocardial infarstion (a) and undergoing cardiosurgery (b).

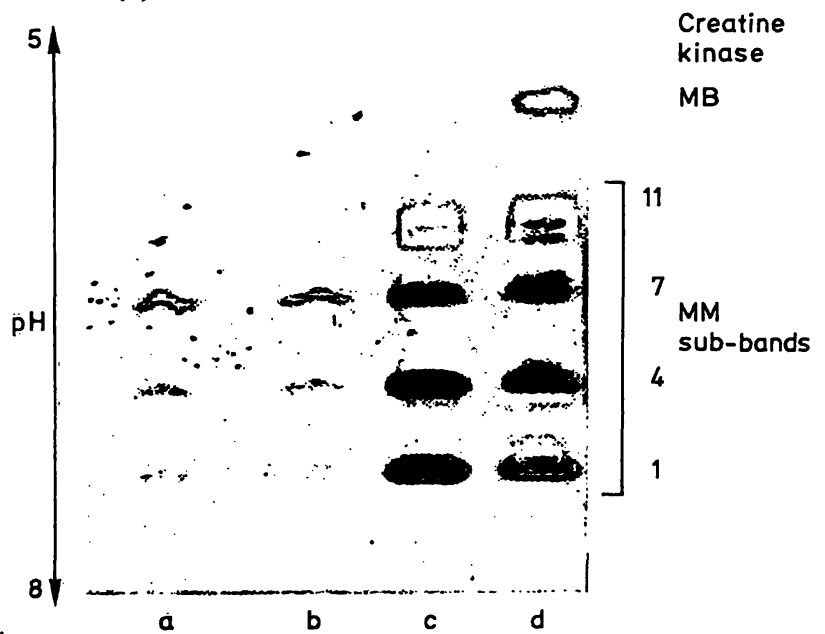

proportion of the creatine kinase-MM 3 sub-band $(38-63 \%)$ as shown by IEF. The samples were kept for 24 hours at $-20^{\circ} \mathrm{C}$, and the immunological creatine kinase-MB test was repeated. Creatine kinaseMB activity was then not detectable in the patients marked with an asterisk in table 4.

The appearance of unusal creatine kinase bands in four patients

1. The first patient (I) was suffering from coronary heart disease and had undergone an aortic valve replacement operation. Using cellulose acetate electrophoresis, no creatine kinase band migrating cathodally to creatine kinase-MM was observed in the 


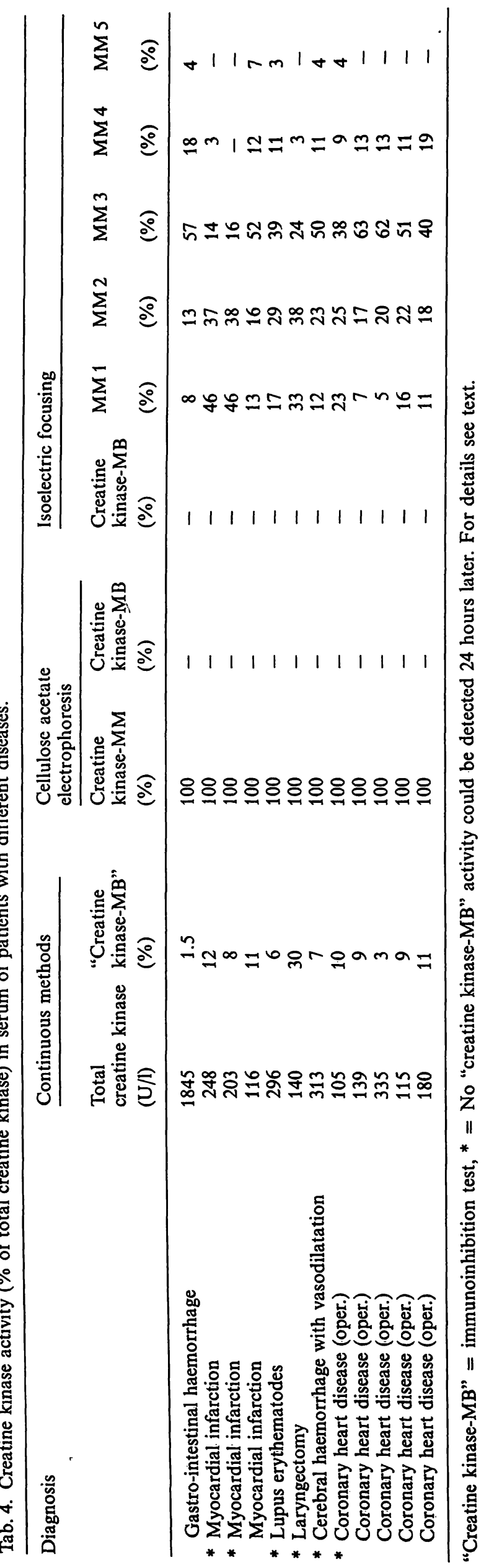

serum. In contrast, isoelectric focusing demonstrated two bands focusing cathodally to creatine kinaseMM sub-band 1 in the sera of this patient (fig. 9).

The appearance of these bands in addition to creatine kinase-MM sub-bands and creatine kinase-MB was noticed after reoperation occasioned by severe complications. Following the postoperative course, the bands were observed on five consecutive days (tab. 5).

2. The second patient (II) had a transmural infarction. He was admitted to the intensive care unit because of the onset of retrosternal pain. Total serum activities were not elevated upon admission.

During the first 24 hours a maximum of total creatine kinase (1469 U/l) and creatine kinase-MB (176 U./1) activities was detectable (tab. 5). In addition to creatine kinase-MM sub-bands and creatine kinase-MB, two bands focusing cathodally to the creatine kinase$\dot{M} M$ subband 1 were observed in the following 24 hours at the maximum of total creatine kinase and creatine kinase-MB activities (fig. 10, samples a and $b$ ).

Five days later the patient suffered a posterior wall reinfarction with cardiogenic shock and died. It is worth noting that after treatment of these sera with anti-creatine kinase-M polyclonal antibodies before IEF, all creatine kinase-MM sub-bands as well as the two additional bands completely disappeared. For comparison, sample c (fig. 10) exhibits a creatine kinase variant pattern typical for patients with myocardial infarction.

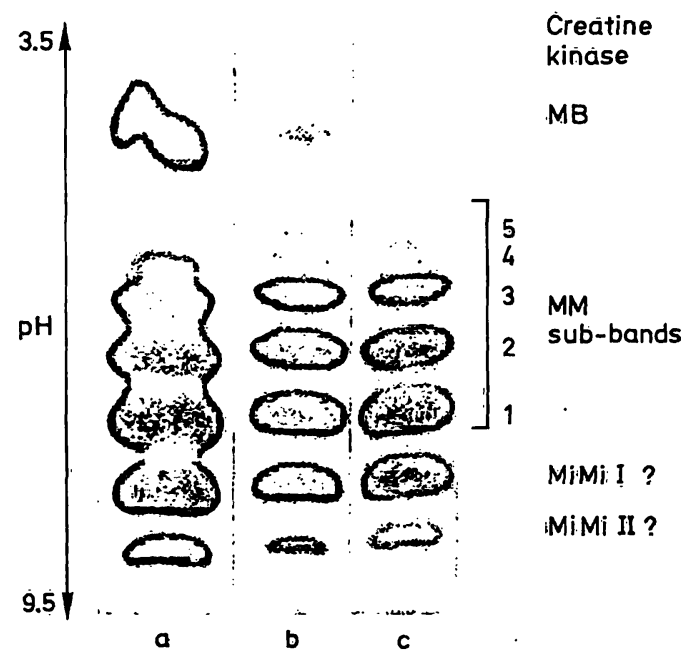

Fig. 9. Separation of creatine kinase isoenzymes by isoelectric focusing in the pH-range 3.5-9.5. The samples a, b and $c$ were taken on three consecutive days from a patient suffered from coronary heart disease following å̉n aorting valve replacement. 


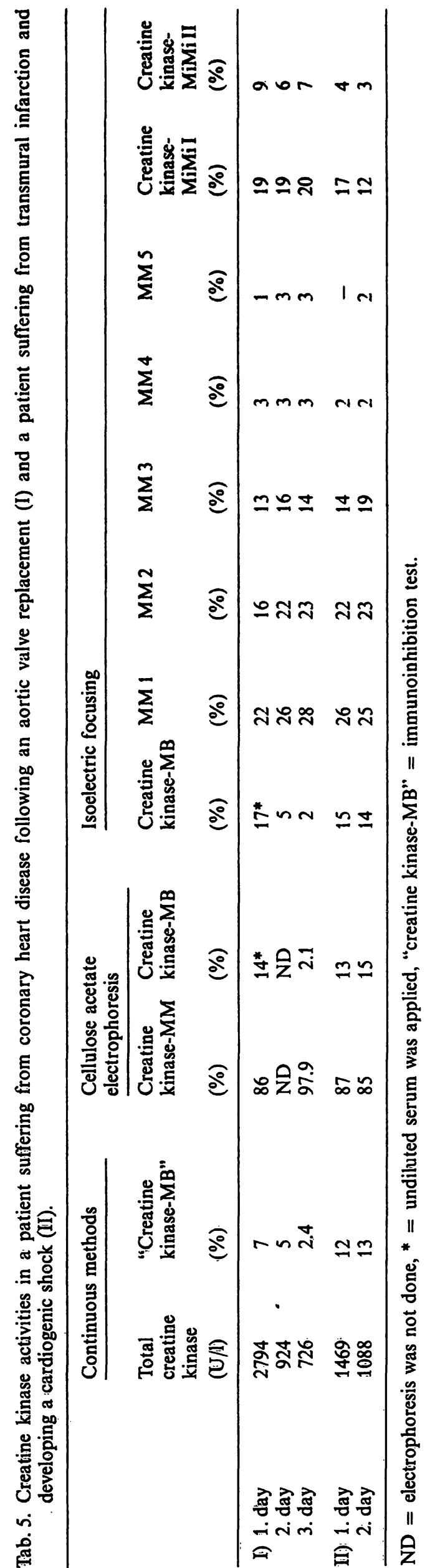

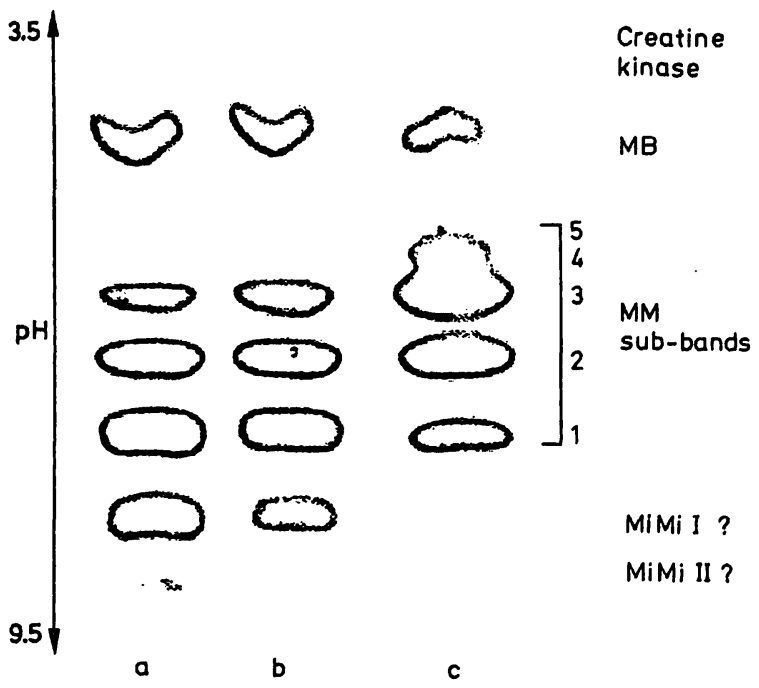

Fig. 10. Migration of creatine kinase variants in IEF using Ampholine pH 3.5-9.5 in Isogel agarose. Samples a and $b$ were obtained from a patient with transmural infarction. Sample c was obtained from another patient with myocardial infarction.

3. In the serum from a patient (III) with WolffParkinson-White syndrome, a total creatine kinase activity of $199 \mathrm{U} / 1$ and a creatine kinase-MB of 294 $\mathrm{U} / 1$ were measured. The creatine kinase isoenzyme patterns obtained by cellulose acetate electrophoresis are shown in figure $11 \mathrm{a}$. Three creatine kinase-isoenzyme bands, i. e. creatine kinase-MM $(17 \%)$, a band migrating between creatine kinase-MM and creatine kinase-MB (26\%) and creatine kinase-MB (57\%) were observed. The zymogram obtained by IEF (fig. $11 \mathrm{~b})$ reveals 3 creatine kinase-MM sub-bands, a minor band focused above the creatine kinase-MM subbands and a major one corresponding to creatine kinase-MB.

4. The serum of another patient (IV), suffering from a metastatic carcinoma of the rectum, revealed two creatine kinase bands upon electrophoresis, one migrating similarly to creatine kinase-MM and the other cathodally to it (fig. 12a). The application of the same sample to IEF on Isogel revealed 3 bands with more alkaline isoelectric points than those observed in the serum of patient I (fig. 12b). No creatine kinase-MM sub-bands were observed. The treatment of this serum with anti-creatine kinase-M before IEF did not reduce the intensity of the bands.

\section{Discussion}

Although isoelectric focusing has been used successfully to isolate, purify and characterize isoenzymes $(24-26)$, this technique has not so far been used for routine determination of creatine kinase-isoenzymes. 


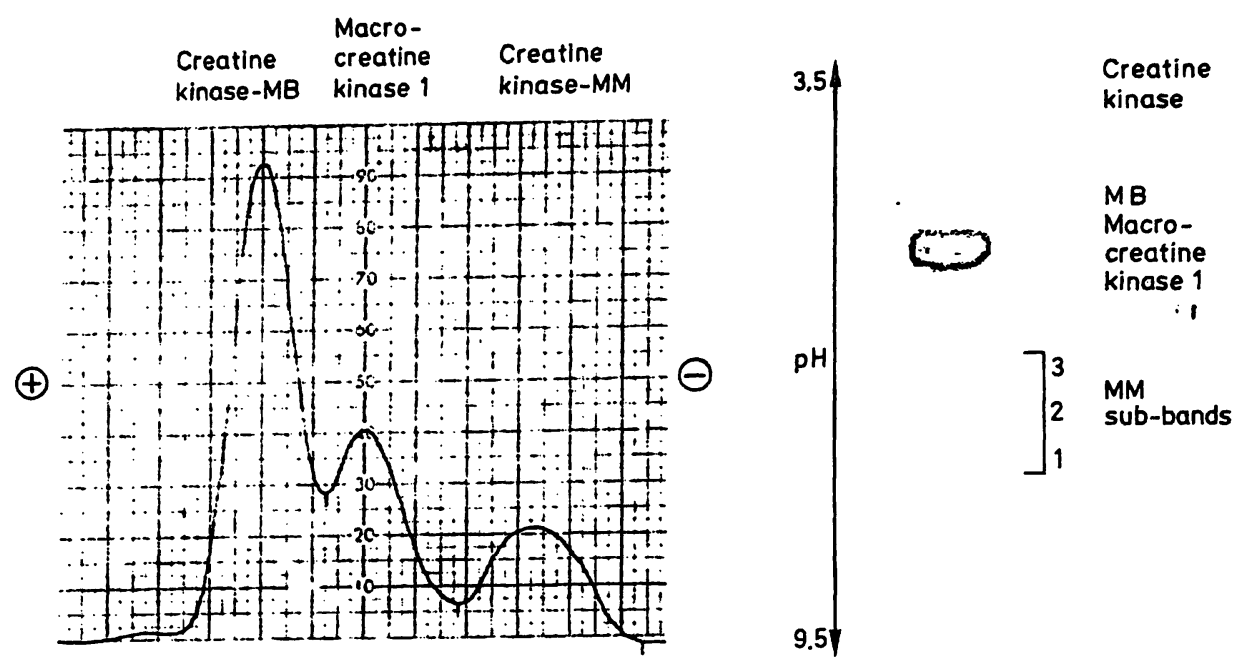

Fig. 11. Migration patterns of creatine kinase variants from a patient with Wolff-Parkinson-White syndrome: a) electrophoresis on cellulose acetate strips, traced with a Beckman CDS-200 densitometer, b) isoelectric focusing with the pH-range 3.59.5 .
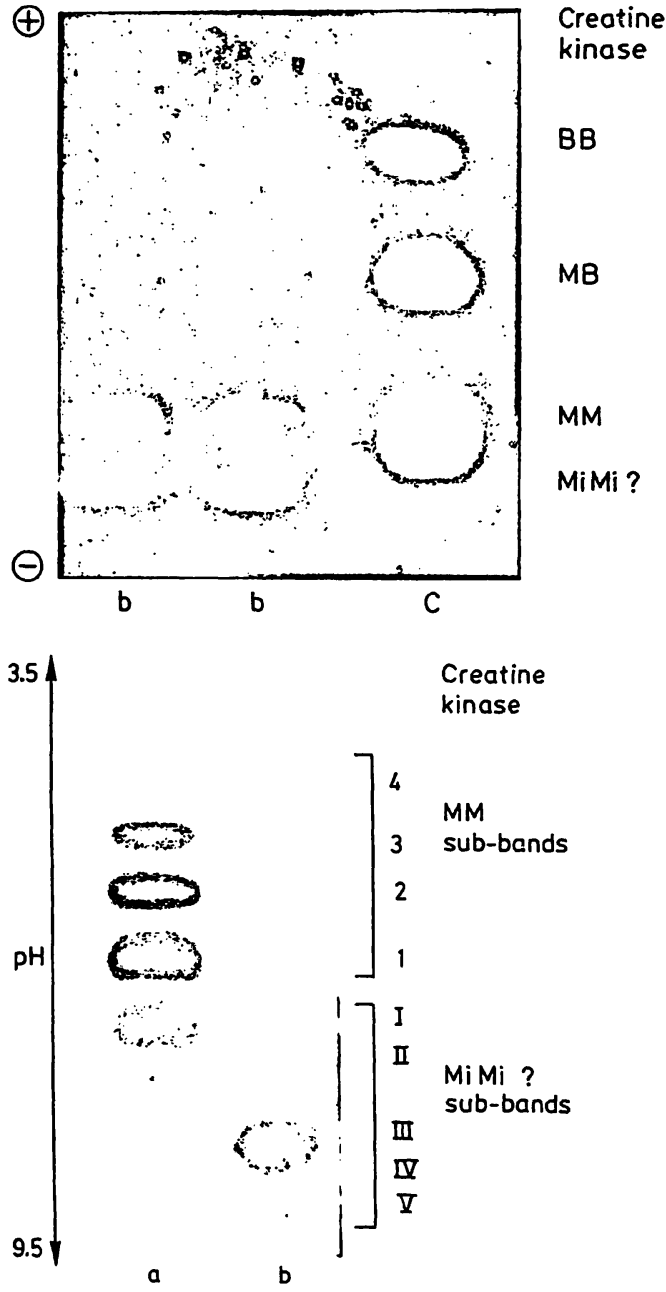

Fig. 12. Separation of creatine kinase isoenzymes from a patient with metastatic rectum carcinoma.

a) Cellulose acetate electrophoresis, b) IEF on Isogel agarose using the pH-range $3.5-9.5$.

$\mathrm{a}=$ sample obtained from a patient with coronary heart disease (sample $\mathrm{c}$ from fig. 9).

$\mathrm{b}=$ sample obtained from a patient with metastatic rectum carcinoma.

$\mathrm{C}=\mathrm{CPK}$ Isotrol.
The present study was undertaken to develop a sensitive and specific assay for the quantitative detection of isoenzymes, based on physical properties of the enzyme molecule as well as on enzyme activity. Due to the high concentration of creatine kinase-isoenzymes at their isoelectric points, tetrazolium salts may be used to give intense, clear bands with a satisfactorily low background. Apart from providing a quantitative detection of creatine kinase-MB, this method yields better information about the heterogeneity of cytosolic and mitochondrial creatine kinase in both tissue extracts and human serum.

This method detected no adenylate kinase activity in human sera, when creatine phosphate was omitted from the reaction medium. Furthermore, the creatine kinase-MM and creatine kinase-MB bands from cellulose acetate electrophoresis are resolved by isoelectric focusing on Isogel into 4-5 creatine kinase-MM sub-bands and one creatine kinase-MB band using an Ampholine of $\mathrm{pH}$ 3.5-9.5. Additional evidence for the specificity of this method is seen in figure 2 . Comparison of creatine kinase-MB isoenzyme levels by isoelectric focusing, the immunoinhibition test and cellulose acetate electrophoresis in patients with proven myocardial infarction showed a high correlation.

The increase of the average concentration of the MBisoenzyme found in this group is in agreement with previous findings $(10,27)$.

In addition, the results obtained with IEF and the immunoinhibition test in patients with recent cardiac surgery, showed a high correlation and are comparable with previous results (28).

A similar high correlation between the immunoinhibition test and IEF $(r=0.987)$ was observed in patients 
without myocardial affections. Surprisingly increased creatine kinase-MB activities (above $6 \%$ ) were found in two patients. One of these patients was suffering from polymyositis. The serum exhibited an additional band between the creatine kinase-MM sub-bands and creatine kinase-MB. Whether this finding is of diagnostic value, has to be clarified. The occurrence of a creatine kinase-MB band in polymyositis has been described (27).

In the serum of the second patient III with WolffParkinson-White syndrome, similar results were obtained by both cellulose acetate electrophoresis and IEF. The quantitative distribution of creatine kinaseMM (17\%), the band migrating between creatine kinase-MM and creatine kinase-MB (26\%) and creatine kinase-MB (57\%) was determined by cellulose acetate electrophoresis (fig. 11 a).

In the serum of another patient with a malignancy, we found increased creatine kinase-BB and low creatine kinase-MB activities upon cellulose acetate electrophoresis (16). By analysing this serum by IEF on Isogel using $\mathrm{pH} 3.5-9.5$, we noticed that the creatine kinase-BB focused almost in the same position as creatine kinase-MB (20). Although the frequency of creatine kinase-BB interference is in the order of $1 \%$ (29), its presence with creatine kinase-MM may reduce the specificity of the IEF method for the diagnosis of myocardial infarction.

When examining patients' sera (tab. 4) a considerable discrepancy was apparent between IEF and the immunoinhibition test. Above $6 \%$ creatine kinase-MB, activity was detected by the immunoinhibition test, whereas no creatine kinase-MB band was observed by IEF or cellulose acetate electrophoresis.

The remarkable characteristic of this finding is the relatively high proportion of the creatine kinaseMM 3 sub-band $(38=63 \%)$ in nine out of 12 sera. We observed also a high proportion of the creatine kinase-MM1 sub-band $(46 \%)$ in the serum of two patients of this group. In addition, we noticed that the apparent creatine kinase-MB in the sera of some patients (tab. 4) of this group was not stable, since storage of these sera for only 24 hours at $-20^{\circ} \mathrm{C}$ caused complete disappearance of creatine kinaseMB activity according to the immunoinhibition test, i.e. measurement on the next day was in complete agreement with the results found by both cellulose acetate electrophoresis and IEF. This phenomenon was not observed in the serum of patients who had undergone a laryngectomy. Concerning the heterogeneity of creatine kinase-MM, some authors (17, $30-31)$ believe that the three creatine kinase-MM and two creatine kinase-MB sub-bands are the result of a postsynthetic variation caused by a thermolabile factor in serum, since only one type of creatine kinase-MB and creatine kinase-MM is present in the sarcoplasm of skeletal and heart muscle. Our results show that the heterogeneity of creatine kinase-MM can be detected at normal as well as at elevated creatine kinase activities in human serum.

The application of serum with elevated creatine kinase activity to Isogel agarose $(\mathrm{pH} \mathrm{5-8)}$ reveals 11 creatine kinase-MM sub-bands (fig. 8). Due to the high sensitivity of the IEF, which allows the detection of 3-4 creatine kinase-MM sub-bands even in sera with low activity, we were now able to compare the creatine kinase variant patterns in:

1. sera with normal activities,

2. sera with elevated (pathological) activities and

3. tissue extracts.

It is generally accepted that localized anoxia and other factors, e. g. trauma, pain and extreme temperature, are the most prevalent causes of cell injury leading to a loss of cell membrane integrity, which results in'a release of cytoplasmic enzymes into the circulation (31).

In contrast to several authors (32-33), our findings in tissue studies confirm that creatine kinase exists in many forms in heart muscle cells (20). We postulate that, depending on the severity of the cell damage, variable amounts of these different forms are released into the serum. This was shown by our results, in which many forms of creatine kinase corresponding with those in tissue extracts were detectable in the serum of several patients.

After release into the serum these forms are quickly eliminated (fig. 9) and in part appear as proteins with lower isoelectric points (34).

Thus, in order to obtain representative and comparable results one should analyse the serum sample immediately, or store frozen.

Our results are not in agreement with those of others who claim that creatine kinase-MM exists in only one form and after release in the serum undergoes postsynthetic transformation $(17,26,32)$.

The creatine kinase-MiMi isoenzyme is distributed widely in human tissue $(15,35)$, and its presence in the sera of patients with malignancies or myocardial infarction is associated with poor prognosis or high mortality $(10-14,16)$. In addition, diagnosis of perioperative myocardial injury is difficult (36), but findings of unusual high postoperative creatine kinaseisoenzyme activities can contribute to the diagnosis (37). 
The potential advantage of the IEF method over others is the ability to isolate, in addition to creatine kinase-MM sub-bands and creatine kinase-MB, other bands located cathodally to the creatine kinase-MM sub-band 1 . It is remarkable that the two bands in the serum of patient I (fig. 9), who had a complicated operation, were observed in the postoperative phase.

The presence of these bands and the disappearance of the creatine kinase-MB band in the late postoperative phase may be explained by the different half life rates of these proteins.

The presence of these bands in the serum of patient II is also associated with poor prognosis (fig. 10). The change in appearance of the various creatine kinase-MM sub-bands suggests that such creatine kinase-MM sub-bands are of particular diagnostic and prognostic importance.

\section{References}

1. Roe, C. R., Limbird, L. E., Wagner, G. S. \& Nerenberg, S. T. (1972) J. Lab. Clin. Med. 80, 577-590.

2. Roberts, R., Gowda, K. S., Ludbrook, P. A. \& Sobel, B. E. (1975) Amer. J. Cardiol. 36, 433-437.

3. Somer, H. \& Konttinen, A. (1972) Clin. Chim. Acta 40, $133-138$.

4. Smith, A. F. (1972) Clin. Chim. Acta 39, 351-359.

5. Nealon, D. A. \& Henderson, A. R. (1975) Clin. Chem. 21, 392-397.

6. Kudirka, P. J., Busby, M. G., Carey, R. N. \& Toren, E. C. (1975) Clin. Chem. 21, 450-452.

7. Würzburg, U., Hennrich, N., Orth, H.-D. \& Lang, H. (1977) J. Clin. Chem. Clin. Biochem. 15, 131-137.

8. Roberts, R., Sobel, B. E. \& Parker, C. W. (1978) Clin. Chim. Acta 83, 141-149.

9. Harm, K., SiragEldin, E. \& Voigt, K. D. (1983) Diagnostic significance of different methods for the characterization of creatine kinase isoenzymes. Abstract, 4th International Congress on Clinical Enzymology, Arlington VA, USA.

10. SiragEldin, E., Gercken, G., Harm, K. \& Voigt, K. D. (1985) J. Clin. Chem. Clin. Biochem. 23, 241-248.

11. Stein, W., Bohner, J., Steinhart, R. \& Eggstein, M. (1982) Clin. Chem. 28, 19-24.

12. Kanemitsu, F., Kawanishi, I., Mizushima, J. \& Okigaki, T. (1984) Clin. Chim. Acta 138, 175-183.

13. James, G. P. \& Harrison, R. L. (1979) Clin. Chem. 25, 943-947.

14. Bark, C. J. (1980) J. Am. Med. Ass. 243, 2058-2060.

15. Kanemitsu, F., Kawanishi, I. \& Mizushima, J. (1982) Clin. Chim. Acta 119, 307-317.

16. SiragEldin, E. \& Klapdor, R. (1985) Klin. Wochenschr. 63, $257-261$.

17. Wevers, R. A., Delsing, M., Klein Gebbink, J. A. G. \& Soons, J. B. J. (1977) Clin. Chim. Acta 86, 323-327.

18. Yasmineh, W. G., Yamada, M. K. \& Cohn, J. N. (1981) J. Lab. Clin. Med. 98, 109-118.

19. Chapelle, J.-P. \& Heusghem, C. (1980) Clin. Chem. 26, $457-462$.

20. SiragEldin, E., Gercken, G., Harm, K. \& Voigt, K. D. (1986) J. Clin. Chem. Clin. Biochem. 24, 283-292.

21. German Society for Clinical Chemistry (1977) J. Clin. Chem. Clin. Biochem. 15, 255-260.
Further evidence for multiple forms of mitochondrial creatine kinase is presented by the serum from patient IV. Although the electrophoresis resulted in two creatine kinase bands, one migrating similar to creatine kinase-MM and the other cathodally to it, no creatine kinase-MM sub-bands were observed in IEF. In addition, we noticed 3 bands with more alkaline isoelectric points than those observed in sera of patients with myocardial injury (fig. 12).

The electrophoretic behaviour of the additional creatine kinase forms noticed in patients I and II (fig. 9 and 10 ) and their reaction with anti-creatine kinase$M$ polyclonal antibodies is comparable to multiple forms of creatine kinase found in human cardiac mitochondria (19). These findings could explain why other authors were unable to detect these forms (mitochondrial?) in the sera of patients with myocardial infarction, using electrophoresis or the immunoinhibition test $(27,38)$.

22. Bohner, J., Stein, W., Steinhart, R., Würzburg, U. \& Eggstein, M. (1982) Clin. Chem. 28, 618-623.

23. Instruction for high-performance analytical electrofocusing in $0.5 \mathrm{~mm}$ thin layer agarose gels, LBK Instruction 1818A, LKB-Produkter AB, Bromma.

24. Burdett, P. E. (1981) J. Forens. Sci. 26, 405-409.

25. Righetti, P. G. (1983) Isoelectric focusing: theory, methodology and applications, Elsevier Biomedical Press, Amsterdam, New York, Oxford.

26. Wevers, R. A., Wolters, R. J. \& Soons, J. B. J. (1977) Clin. Chim. Acta 78, 271-276.

27. Lang, H., ed. (1981) Creatine kinase isoenzymes, Springer Verlag, Berlin, Heidelberg, New York.

28. Homburger, H. A. \& Jacob, G. L. (1980) Clin. Chem. 26, $861-866$.

29. Lang, H. \& Würzburg, U. (1982) Clin. Chem. 28, 14391447.

30. Falter, H., Michelutti, L., Mazzuchin, A. \& Whiston, W. (1981) Clin. Biochem. 14, 3-7.

31. Robbins, S. L. (1974) Pathologic basis of disease. W. B. Saunders Co., Philadelphia, PA.

32. George, S., Ishikawa, Y., Perryman, M. B. \& Roberts, R. (1984) J. Biol. Chem. 259, 2667-2674.

33. Grace, A. M., Perryman, M. B. \& Roberts, R. (1983) J. Biol. Chem. 258, $15346-15354$.

34. Dice, J. F. \& Goldberg, A. L. (1975) Proc. Natl. Acad. Sci. USA 72, 3893-3897.

35. Wevers, R. A., Mul-Steinbusch, M. W. F. J. \& Soons, J. B. J. (1980) Clin. Chim. Acta 101, 103-111.

36. Balderman, S. C., Bhayana, J. N., Steinbach, J. J., Masud, A. R. Z. \& Michalek, S. (1980) Ann. Thorac. Surg. 30, $370-377$.

37. Keshgegian, A. A. \& Marchant, B. L. (1983) Clin. Chem. $29,1727-1730$.

38. Rock, R. C., Dreskin, R., Kickler, T. \& Wimsatt, T. (1975) Clin. Chim. Acta 62, 159-162.

Dr. rer. nat. E. SiragEldin

Abteilung für Klinische Chemie

der Medizinischen Klinik

Universitäts-Krankenhaus Eppendorf

Martinistraße 52

D-2000 Hamburg 20 